\title{
Recognition of contact calls by the budgerigar (Melopsittacus undulatus)
}

\author{
NASIMA J. ALI, SUSAN FARABAUGH, and ROBERT DOOLING \\ University of Maryland, College Park, Maryland
}

\begin{abstract}
Playback studies have been used to assess whether birds recognize the calls and songs of other birds. In this experiment, contact calls were recorded from three pairs of budgerigars. These calls were then used as stimuli in playback experiments. Calls were stored on a computer and played to the birds either randomly or in response to calling. The bird's vocal responses to these stimuli were recorded and counted. Results indicate that the birds showed a preference for particular calls. Overall, the birds responded more frequently to their mate's call than to the calls of other birds.
\end{abstract}

The budgerigar (Melopsittacus undulatus) is a highly social and vocal parrot indigenous to Australia. Budgerigars have a complex vocal repertoire consisting of a number of call types and a long, rambling song (Dooling, 1986; Farabaugh, Brown, \& Dooling, 1992). The domesticated budgerigar has been a favorite subject for studies of vocal learning and auditory perception (see, e.g., Brockway, 1969; Brown, Dooling, \& O'Grady, 1988) with particular emphasis on contact calls (Dooling, Brown, Klump, \& Okanoya, 1992; Park \& Dooling, 1985, 1986; Trillmich, 1976).

Of the various call types in the repertoire, contact calls are the most frequently produced and are also the most common element in budgerigar song (Farabaugh et al., 1992). The average contact call, given by both males and females, is about $150 \mathrm{msec}$ in duration, with a high degree of frequency modulation. Most of the energy in contact calls is between 2 and $4 \mathrm{kHz}$. This call is typically quite loud, being produced at a peak sound pressure level of $90 \mathrm{SPL}$ measured $1 \mathrm{~m}$ from the bird. Birds ordinarily have one or two dominant contact calls (i.e., calls that are used $80 \%-90 \%$ of the time) in their repertoire, with a few other types of contact calls given much less frequently (Farabaugh, Linzenbold, \& Dooling, in press).

Though each bird in our study had a different dominant contact-call type, budgerigars can learn to produce contact-call types of other birds in their repertoires (Farabaugh et al., in press). Budgerigars give the contact call in the context of movement that may lead to separation: When flying some distance, drifting while feeding on open fields, flying down to the water's edge to drink, or finding a perch at night to roost, the call seems

The research for this project was supported by an NSF grant through the Program for Research Experience for Undergraduates (REU) to the University of Maryland, College Park, Maryland, and by NIH Grant DC-00198 to R.D. Correspondence should be addressed to R. Dooling, Department of Psychology, University of Maryland, College Park, MD 20742. to keep pairs and flocks together. Also, flying birds are attracted to calling caged birds, even when the latter are visually isolated (Wyndham, 1980). We know from previous work that budgerigars can discriminate among contact calls in an operant task and can distinguish between individuals based on these calls (Brown et al., 1988; Dooling et al., 1992). Moreover, they can also learn in an operant task to classify (recognize) upwards of 20 different contact calls from different birds (Park \& Dooling, 1985, 1986).

It is obviously important for social animals to be able to recognize one another, and there is a wealth of evidence from field studies that birds can recognize neighbors by song (see, e.g., Searcy, McArthur, Peters, \& Marler, 1981; Stoddard, Beecher, Horning, \& Campbell, 1991) as well as recognize other individuals or mates by calls (see, e.g., Beecher \& Stoddard, 1989; Mundinger, 1970; White, 1971). The present experiment addresses a similar question in budgerigars-namely, whether budgerigars respond preferentially to different contact calls from different individuals. Responding in this case is defined as calling back in response to a contact call presented by computerized playback.

\section{METHOD}

\section{Subjects}

Three mated pairs of unrelated budgerigars from the same aviary were housed together in the same cage during this experiment. They formed their pair bonds before the experiment began-in fact, two of the three pairs had bred at least once.

\section{Repertoire Sampling}

The experimental playback consisted of the dominant contact calls (e.g., the most frequently occurring contact call type in each bird's repertoire) of the 6 subjects. To establish the dominant call of each bird, a sample of 30-50 contact calls was elicited, recorded on audiotape, and displayed on a KAY DSP 5500 real-time analyzer. Two individual renditions of each bird's dominant contact-call type were captured on separate computer files $(20,480 / \mathrm{sec}$ sampling rate) and later used as playback stimuli. Sonograms of contact calls given by the different birds in this experiment are shown in Figure 1. 

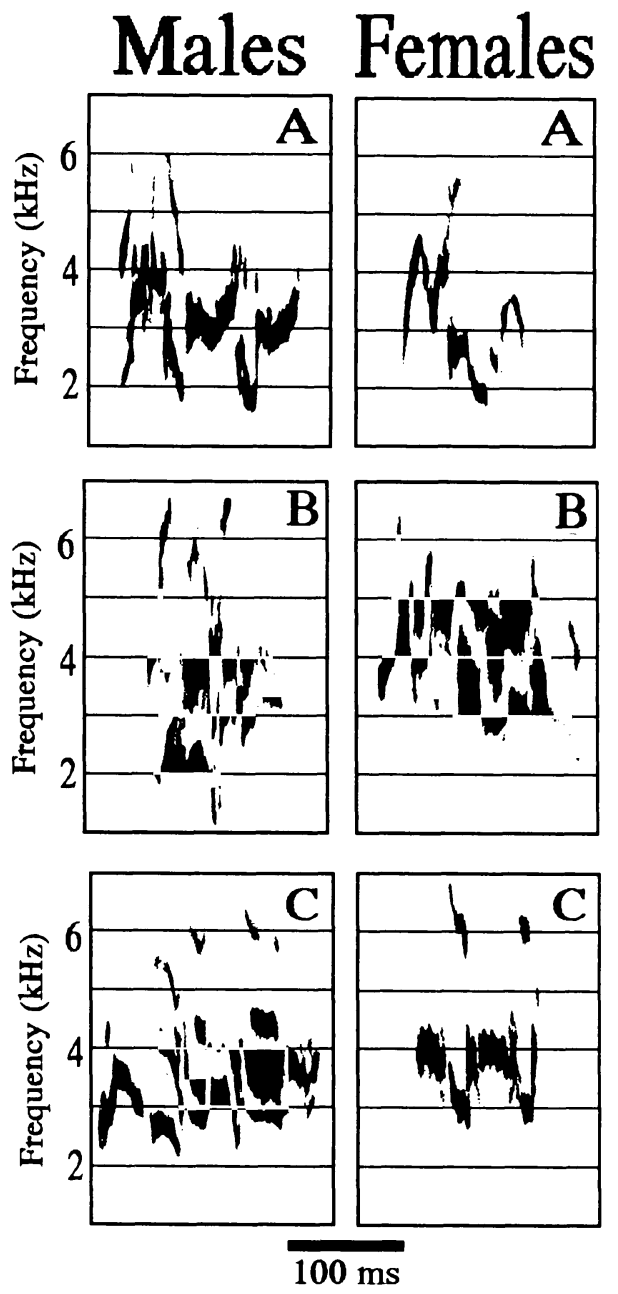

Figure 1. Sonograms of the dominant contact call types of the 6 subjects. These calls were recorded on a four-track TEAC tape recorder and analyzed with a 7800 Digital Sona-graph with a bandwidth of $300 \mathrm{~Hz}$. Frequency lines are $2000 \mathrm{~Hz}$. The time marker is $\mathbf{1 0 0} \mathrm{msec}$.

\section{Playback Procedure}

The birds were removed from the home cage one at a time and placed in the testing cage that was housed in a room-size sound-attenuated IAC chamber with a one-way reflective window. Each subject was placed near the window, where it could see the remaining 5 birds in the home cage positioned outside; this allowed the subject a view of the other birds while it remained in acoustic isolation.

The presentation of the six contact call stimuli and the recording of the subject's response were controlled by computer. The contact calls were presented at a peak sound pressure level of about $70 \mathrm{~dB}(A) S P L$, with an average random interval of between 20 and $30 \mathrm{sec}$. At the beginning of each presentation trial, the computer turned on a Marantz audio cassette recorder that was connected to a microphone in the test cage. The stimulus was then played out to a speaker above the test cage, and the tape recorder was turned off again $500 \mathrm{msec}$ after the end of the stimulus playback. Thus, the stimulus and the subject's response were recorded on audiotape. By means of a voice-actuated switch, the computer tallied the number of responses to each contact call. For each trial, the stimulus call type, the length of the preceding intertrial interval (ITI), and the presence or absence of a response by the subject were saved to a file. Typically, a test session consisted of 70-150 trials. To verify that responses were contact calls (as opposed to cage noises, warble song, etc.), we scanned the audiotapes with the Kay real-time sonograph. Only contact calls were counted as responses for our calculations.

The playback program was interactive. If the subject vocalized during the ITI, the next trial was initiated. This feature encouraged birds (usually the females) that called the least frequently during the experiment to call as if they were in a duet. If no calling occurred, the trial began after the randomly chosen interval.

As mentioned above, two stimulus sets, each consisting of different renditions of the same six call types, were tested. There was no significant difference in the pattern of response between the two stimulus sets, indicating that the birds did recognize individuals by their calls. The data from the two sets were then pooled for subsequent analysis.

\section{Statistical Analysis}

We used chi-square to test the null hypothesis that birds are equally likely to respond to any contact call by comparing, for each bird, the observed number of responses to each call type with the expected number of responses, which was calculated from the number of times that each call type was presented to that bird. We also tested the pooled data of all of the birds and compared the observed total number of responses to each call type with the expected total number of responses, which was calculated from the number of times that each call type was presented to all 6 birds.

\section{RESULTS}

The birds responded to a fraction of the stimuli. The response rates ranged from $1 \%-36 \%$, but most birds' response rate was between $5 \%$ and $8 \%$. Five birds showed a significant preferential response to the six stimuli, whereas 1 bird, Bf (female), responded equally to all of the call types (see Table 1). Three birds (Am [male], Af, $\mathrm{Bm}$ ) showed a significant preference for their mates' call type. Two birds, $\mathrm{Cm}$ and $\mathrm{Cf}$, showed a trend of greater response to the call of their mates, but the response pattern was not significantly different from random. One bird, Bf, had no preference for her mate's call. It is interesting to note that the bird that showed absolutely no preference for any of the call types was, by far, the most responsive bird in the study (428 responses to 1,182 stimuli).

Grouping the data for all of the birds showed that no one call type was preferred. But, as a group, the birds gave differential responses to call types on the basis of social relationship (i.e., calls of mate, self, other males, and other females). The birds as a group recognized and

Table 1

Results of Chi-Square Test on Responses

to Six Stimuli Calls and on Four Groupings of Responses

\begin{tabular}{lcccccc}
\hline & & \multicolumn{2}{c}{$\begin{array}{c}\text { Response } \\
\text { to Six Calls }\end{array}$} & & \multicolumn{2}{c}{$\begin{array}{c}\text { Response } \\
\text { to Four Groups }\end{array}$} \\
\cline { 3 - 4 } \cline { 6 - 7 } Subject & $n$ & $\chi^{2}$ & $p$ & & $\chi^{2}$ & $p$ \\
\hline Am & 174 & 75.512 & $<.001$ & & 51.798 & $<.001$ \\
Af & 115 & 18.276 & $=.003$ & & 16.582 & $=.001$ \\
Bm & 119 & 33.355 & $<.001$ & & 21.961 & $<.001$ \\
Bf & 428 & 6.936 & $=.225^{*}$ & & 3.517 & $=.319^{*}$ \\
Cm & 167 & 15.824 & $=.007$ & & 6.699 & $=.082^{*}$ \\
Cf & 24 & 11.146 & $=.049$ & 6.160 & $=.104^{*}$ \\
\hline
\end{tabular}

Note-Cf has such a small $n$ that her chi-square result is not reliable. Degrees of freedom for the six calls was 5; for the four groups, it was $3 . \mathrm{m}=$ male; $\mathrm{f}=$ female. $\quad$ *Not significant for $p \leq .05$. 


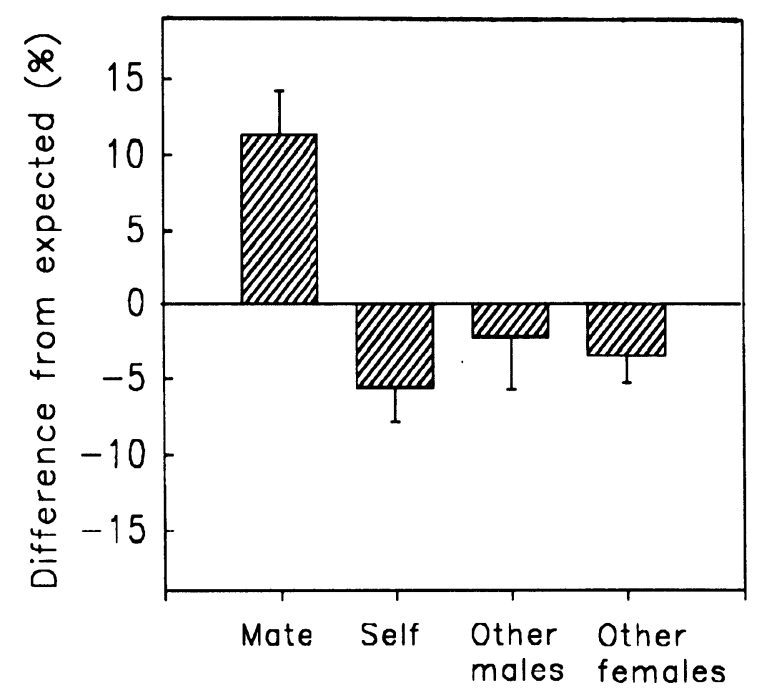

Identity of Caller

Figure 2. The average response of the 6 birds to calls grouped by the four categories of social relationships. The subjects favored their own mates. The birds respond to their mates' calls at a significantly greater rate than that expected by chance.

responded to the calls of their mates an average of $15 \%$ more often than would be expected by chance (Figure 2).

\section{DISCUSSION}

Various studies have shown that territorial songbirds respond more aggressively to songs of strangers than to songs of neighbors (see, e.g., Falls, 1982; Weedon \& Falls, 1959), and aggessive response to a neighbor's song will increase if the song is played from a territory edge that is not shared with that neighbor (Brooks \& Falls, 1975). Birds not only recognize their neighbors' songs but adjust their response if they perceive that a neighbor's song is coming from an unexpected direction.

Studies of call recognition differ from those of song recognition because responses to playbacks of recorded calls are not necessarily ag gressive, nor do they have to do directly with mate attraction. Rather, the bird calls back, in greeting, to calls of its mate or social companion. Various studies of colonially breeding seabirds have shown that birds respond more to their mate's call than to a neighbor's or a stranger's call (see, e.g., Beer, 1970; White, 1971). In the budgerigar, contact calls are also given in the context of greeting after separation, and we found that response was greatest to a mate's call. In other words, contact calls of budgerigars encode individual identity.

The success of future playback studies using contact calls in budgerigars will depend on whether response rate can be increased. If so, these procedures might prove useful in examining finer discriminations and other relationships within budgerigar social groups, including mates, siblings, and familiar versus unfamiliar birds. Such studies go beyond simple discrimination and categorization and bear on the function of contact calls in mediating budgerigar social behavior.

\section{REFERENCES}

Beecher, M. D., \& Stoddard, P. K. (1989). Signaling systems for individual recognition-an information theory approach. Animal Behaviour, 38, 248-261.

BEER, C. J. (1970). Individual recognition of voice in the social behavior of birds. In D. S. Lehrman, R. A. Hinde, \& E. Shaw (Eds.), Advances in the study of behavior (pp. 27-74). New York: Academic Press.

BROCKWAY, B. F. (1969). Roles of budgerigar vocalization in the integration of breeding behavior. In R. A. Hinde (Ed.), Bird vocalizations (pp. 131-158). Cambridge: Cambridge University Press.

Brooks, R. M., \& FALLs, J. B. (1975). Individual recognition by song in white-throated sparrows: I. Discrimination of songs of neighbors and strangers. Canadian Journal of Zoology, 53, 879-888.

Brown, S., Dooling, R. J., \& O'Grady, K. (1988). Perceptual organization of acoustic stimuli by the budgerigar (Melopsittacus undulatus): III. Contact Call. Journal of Comparative Psychology, 102, 236-247.

Dooling, R. J. (1986). Perception of vocal signals by budgerigars (Melopsittacus undulatus). Experimental Biology, 45, 195-218.

Dooling, R. J., Brown, S. D., Klump, G. M., \& Okanoya, K. (1992). Auditory perception of conspecific and heterospecific vocalizations in birds: Evidence for special processes. Journal of Comparative Psychology, 106, 20-28.

FALLS, J. B. (1982). Individual recognition by sounds in birds. In D. E. Kroodsma \& E. H. Miller (Eds.), Acoustic communication in birds: Song learning and its consequences (pp. 237-278). New York: Academic Press.

Farabaugh, S. M., Brown, E. D., \& Dooling, R. J. (1992). Analysis of warble song of the budgerigar, Melopsittacus undulatus. Bioacoustics, 4, 111-130.

Farabaugh, S. M., Linzenbold, A., \& Dooling R. J. (in press). Vocal plasticity in budgerigars (Melopsittacus undulatus): Evidence for social factors in the learning of contact calls. Journal of Comparative Psychology.

MUNDINGER, P. (1970). Vocal imitation and individual recognition of finch calls. Science, 168, 480-482.

Park, T. J., \& Dooling, R. J. (1985). Perception of species-specific contact calls of budgerigars (Melopsittacus undulatus). Journal of Comparative Psychology, 99, 391-402.

Park, T. J., \& Dooling, R. J. (1986). Perception of degraded vocalizations by budgerigars (Melopsittacus undulatus). Animal Learning \& Behavior, 14, 359-364.

Searcy, W. A., McArthur, P. D., Peters, S. S., \& Marler, P. (1981). Response of male song and swamp sparrows to neighbor, stranger, and self songs. Behaviour, 77, 152-166.

Stoddard, P. K., Beecher, M. D., Horning, C. L., \& Campbell, S. E. (1991). Recognition of individual neighbors by song in the song sparrow, a species with song repertoires. Behavioral Ecology \& Sociobiology, 29, 211-215.

TrILLMICH, F. (1976). Learning experiments on individual recognition in budgerigars (Melopsittacus undulatus). Zeitschrift fur Tierpsychologie, 41, 372-395.

WeEdon, J. S., \& FalLs, J. B. (1959). Differential response of male ovenbirds to recorded song of neighboring and more distant animals. Animal Behaviour, 7, 340-351.

White, S. J. (1971). Selective responsiveness by the gannet (Sula bassana) to played-back calls. Animal Behaviour, 19, 125-131.

WYNDHAM, E. (1980). Diurnal cycle, behavior and social organization of the budgerigar (Melopsittacus undulatus). Emu, 80, 25-33.

(Manuscript received May 19, 1993.) 